AZEVEDO, AM; ANDRADE JÚNIOR, VC; SOUSA JÚNIOR, AS; SANTOS, AA; CRUZ, CD; PEREIRA, SL; OLIVEIRA, AJM. 2017. Eficiência da estimação da área foliar de couve por meio de redes neurais artificiais. Horticultura Brasileira 35: 014-019. DOI - http://dx.doi.org/10.1590/S0102-053620170103

\title{
Eficiência da estimação da área foliar de couve por meio de redes neu- rais artificiais
}

\author{
Alcinei M Azevedo; Valter C Andrade Júnior²; Aderbal S Sousa Júnior²; Albertir A Santos²; Cosme D \\ Cruz$^{1}$; Samuel L Pereira²; Altino JM Oliveira ${ }^{2}$ \\ ${ }^{1}$ Universidade Federal de Viçosa (UFV), Viçosa-MG, Brasil; alcineimistico@hotmail.com; cdcruz@ufv.br; ${ }^{2}$ Universidade Federal \\ dos Vales do Jequitinhonha e Mucuri (UFVJM), Diamantina-MG, Brasil; valterjr@ufvjm.edu.br; aderjunior.agro@gmail.com; albert. \\ ap.santos@hotmail.com; samuel.luan@hotmail.com; altinomendes@hotmail.com
}

\section{RESUMO}

A estimativa da área foliar na couve é importante, pois medidas diretas são difíceis e imprecisas, devido ao tamanho da folha, a irregularidade da superfície foliar de alguns genótipos, a necessidade de equipamentos caros e de muita mão-de-obra. Objetivou-se verificar a eficiência da estimação da área foliar de couve por meio de RNAs e constatar a eficiência desta estratégia em comparação com o uso da área foliar observada. O experimento foi conduzido em delineamento de blocos casualizados com três repetições, 22 acessos e quatro plantas por parcela. Desenvolveram-se perceptrons de multicamadas utilizando 50 folhas por acesso, destinando-se $70 \%$ para treinamento, $15 \%$ para a validação cruzada (early-stop) e 15\% para teste. Foram testadas 39 configurações de rede perceptron de multicamadas. As RNAs foram eficientes para estimar a área foliar da couve a partir do comprimento e largura do limbo foliar. A área foliar estimada pela RNA é indicada para a seleção de plantas por ser de fácil obtenção, ser um método não destrutivo, apresentar alta correlação fenotípica e genética com a área foliar observada e maior herdabilidade.

Palavras-chave: Brassica oleracea var. acephala, perceptron de multicamadas, seleção indireta, inteligência computacional.

\begin{abstract}
Increased efficiency of selection for leaf area in kale using artificial neural networks

The estimation of leaf area in kale is important because direct measurements are difficult and inaccurate, due to the leaf size, the irregularity of the leaf surface of some genotypes, the need for expensive equipment and intensive labor. The objective was to verify the efficiency of artificial neural networks to estimate the leaf area and verify the efficiency of the use of the estimated area in the selection process compared with the observed area. The experiment was conducted in a randomized block design with three replications, 22 accesses and four plants per plot. Multilayer perceptrons were developed using 50 leaves per access, 70\% designed for training, $15 \%$ for cross-validation (early-stop) and $15 \%$ for testing. 39 perceptron multilayer network settings were tested. The RNAs were efficient to estimate leaf area from the length and width of the leaf blade. The leaf area estimated by the RNA is indicated for the selection of plants due to its easily access and due to be a non-destructive method, having high phenotypic and genetic correlation with leaf area observed and higher heritability.
\end{abstract}

Keywords: Brassica oleracea var. acephala, multilayer perceptron, indirect selection, genetic parameters.

(Recebido para publicação em 20 de fevereiro de 2015; aceito em 16 de março de 2016) (Received on February 20, 2015; accepted on March 16, 2016)

\begin{abstract}
A área foliar é um dos principais parâmetros do crescimento vegetal, pois está relacionada com diversos processos fisiológicos da planta, tais como fotossíntese, respiração e transpiração (Silva et al., 2008; Ghoreishi et al., 2012). Esta característica ganha maior importância para culturas como a couve (Brassica oleracea var. acephala) cujas folhas são de interesse comercial.

A área foliar é frequentemente determinada utilizando scanners de mesa ou portátil. Além destes equipamentos
\end{abstract}

serem caros, ser um método destrutivo e demandar muito tempo e mão-de-obra, não são muito adequados para folhas grandes (Ahmadian, 2012) como as encontradas em couve. Outra grande dificuldade para a mensuração da área foliar em couve por este método é que alguns genótipos possuem folhas de superfície bastante engruvinhada. A consequência desta irregularidade na superfície foliar é que sua área pode ser superestimada ou subestimada, o que pode levar à menor eficiência no processo de seleção de genótipos superiores.

Uma alternativa para a obtenção da área foliar é sua estimação por meio de medidas geométricas como o comprimento e largura do limbo (Odabas et al., 2013). A vantagem deste método é que a mensuração da largura e comprimento pode ser feito com alta precisão em folhas de couve, sendo um método barato, rápido, menos laborioso e não destrutivo. O comprimento e largura do limbo foliar tem sido utilizados para a estimação da área foliar em diver- 
sas hortaliças como tomate e pepino (Blanco \& Folegatti, 2003; Cho et al., 2007), brócolis (Stoppani et al., 2003), morango (Demirsoy et al., 2005), abobrinha (Rouphael et al., 2006), rabanete (Salerno et al., 2005) e pimenta (De Swart et al., 2004; Ahmadian, 2012).

A área foliar pode ser estimada a partir do comprimento e largura do limbo foliar por modelos matemáticos utilizando abordagem linear ou não-linear (Rouphael et al., 2006, Silva et al., 2008). Alternativamente, pode-se recorrer à técnica de redes neurais artificiais (RNAs). As RNAs têm demonstrado grande habilidade para resolver sistemas não lineares complexos. Esta técnica apresenta a vantagem de ser não-paramétrica, tolerar a perda de dados, e não necessitar informações detalhadas sobre o sistema a ser modelado (Silva et al., 2014).

Desta forma, objetivou-se verificar a eficiência da estimação da área foliar da couve por meio de RNAs e constatar a eficiência desta estratégia em comparação com o uso da área foliar observada.

\section{MATERIAL E MÉTODOS}

O experimento foi conduzido no Setor de Olericultura, localizado no campus JK da UFVJM, Diamantina-MG (18²'01'"S; 4334'20"O, altitude $1387 \mathrm{~m})$. O solo é classificado como Neossolo Quartzarênico Órtico típico (Embrapa, 2006). No período de condução do experimento, a temperatura média foi de $17,4^{\circ} \mathrm{C}$ com umidade relativa do ar de $72,1 \%$, havendo poucas oscilações no decorrer deste período.

Foram avaliadas três cultivares comerciais e dezenove acessos de couve do banco de germoplasma da UFVJM utilizando-se o delineamento em blocos casualizados com três repetições e quatro plantas por parcela, sendo doze acessos oriundos de coletas em propriedades rurais na região de Diamantina-MG (UFVJM-3, UFVJM-7, UFVJM-8, UFVJM-10, UFVJM-13, UFVJM-19, UFVJM-21, UFVJM-24, UFVJM-26, UFVJM-32, UFVJM-34 e UFVJM-36) e sete acessos doados pela Universidade Federal de Lavras (UFLA-1, UFLA-3, UFLA-5, UFLA-6, UFLA-8, UFLA-11 e UFLA-12). As cultivares comerciais foram: Couve Manteiga 900 Legitima Pé Alto da empresa Feltrin ${ }^{\circledR}$ (COM-1); Couve Manteiga da empresa Vidasul baby ${ }^{\circledR}$ (COM-2); e Couve de Folha Manteiga Geórgia da empresa Horticeres ${ }^{\circledR}$ (COM-3).

Para a instalação do experimento, foram coletadas em 07 de junho de 2013 brotações para a formação das mudas pelo sistema de estaquia verde coletando-se as brotações laterais, com três a quatro centímetros de altura e dois folíolos, no terço basal das plantas matrizes. Após a coleta, os brotos foram plantados em bandejas de isopor de 72 células preenchidas com substrato comercial e mantidas em casa de vegetação por 30 dias, a fim de garantir o melhor enraizamento das brotações. No dia 07 de julho de 2013 as mudas foram transplantadas para canteiros com largura aproximada de 2,5 m e 30 $\mathrm{cm}$ de altura, utilizando-se espaçamento de 1,0x0,5 m. As adubações de solo e cobertura foram realizadas de acordo com as recomendações para a cultura (Filgueira, 2008).

Entre 07 de agosto e novembro de 2013, realizou-se colheitas de folhas comercializáveis de 14 em 14 dias. Foram consideradas como folha comercializável aquelas completamente expandidas com comprimento do limbo foliar maior que $15 \mathrm{~cm}$ e sem sinais de senescência (Azevedo et al., 2012). Em cada folha foi avaliado o comprimento e largura do limbo foliar (medido com régua graduada em centímetros) e a área foliar $\mathrm{em}^{2}$ (cada folha foi escaneada utilizando um Scanner HP Photosmart C4480, sendo sua área estimada com o auxilio do software Image Pro Plus 4.5).

Para o desenvolvimento das redes MLP (Multi-Layer-Perceptron), foi utilizado o Neural Network Toolbox do software Matlab (versão 8.1.0.604), com algoritmo backpropagation e otimização Levemberg-Marquadt. No processo de treinamento da MLP foram utilizados os dados de comprimento e largura do limbo foliar como variáveis de entrada e a área foliar observada como saída desejada. Foram utilizadas informações de 50 folhas de cada genótipo estudado, totalizando 1100 folhas. Deste conjunto de dados foram destinadas as informa- ções de 770 folhas para o treinamento (70\%), 165 folhas para a validação cruzada [early stopping (15\%)] e 165 folhas para o teste (15\%).

Visando garantir que cada parâmetro de entrada recebesse igual atenção durante o treinamento, tanto os dados de entrada quanto os de saída, foram padronizados para o intervalo entre 0 e 1 pela seguinte equação $V_{n}=[1+$ $\left.\left(\mathrm{V}_{\text {obs }}-\mathrm{V}_{\max }\right)\right] /\left(\mathrm{V}_{\max }-\mathrm{V}_{\min }\right)$, em que: $\mathrm{V}_{\mathrm{n}}$ é o valor normalizado, adimensional; $\mathrm{V}_{\text {obs }}$ é o valor observado; $\mathrm{V}_{\min }$ é o valor mínimo da amostra e $\mathrm{V}_{\text {max }}$ é o valor máximo da amostra. Os menores valores encontrados na amostra de plantas avaliadas foram $10,40 \mathrm{~cm}, 7,00 \mathrm{~cm}$ e $65,40 \mathrm{~cm}^{2}$ para o comprimento, largura e área do limbo foliar, respectivamente. Já os maiores valores encontrados foram $34 \mathrm{~cm}, 26,50 \mathrm{~cm}$, e $602,75 \mathrm{~cm}^{2}$ para o comprimento, largura e área do limbo foliar, respectivamente.

O número máximo de épocas de treinamento foi arbitrado como 1000, o EQM (erro quadrático médio) mínimo para parada foi estabelecido como $1.0 \times 10^{-7}$ e o maior número de falhas sucessivas na validação (early stopping) foi definido como 6. Foram testadas todas as combinações possíveis de rede considerando uma, duas e três camadas escondidas e dois, quatro e seis neurônios por camada, constituindo-se em 39 configurações. Tendo em vista que, no início do treinamento, os parâmetros livres são gerados aleatoriamente e que esses valores iniciais podem influenciar o resultado final do treinamento (Soares et al., 2014), cada configuração de RNA foi treinada 100 vezes. A seleção da melhor rede treinada foi feita considerando o menor EQM encontrado em todos os treinamentos realizados.

A função de ativação para os neurônios da(s) camada(s) escondida(s) foi a tangente hiperbólica dada por $\mathrm{T}_{\text {ansig }}(\mathrm{x})=$ $2 /[1+\exp (-2 \mathrm{x})-1]$, já para a camada de saída utilizou-se a função linear dada por $\operatorname{Lin}(x)=x$. Segundo Silva et al. (2012), a função linear não satura e consequentemente possibilita que a rede gere saídas fora da região $[-1,+1]$. Segundo este mesmo autor, deseja-se que a rede seja capaz de modelar combinações de parâmetros de entrada que gerem saídas fora desta região visto que as sensibilidades 
máximas obtidas a partir do conjunto experimental não são necessariamente as máximas sensibilidades possíveis. Para a conversão da escala da área foliar obtida pelas RNAs para a unidade de centímetros quadrados realizou-se a etapa de desnormatização. Para isso, utilizou-se a seguinte expressão: $\mathrm{V}_{\mathrm{dn}}=$ $\left[\mathrm{V}_{\text {max }}+\left(\mathrm{V}_{\mathrm{n}}-1\right)_{*}\left(\mathrm{~V}_{\text {max }}-\mathrm{V}_{\text {min }}\right)\right]$, em que: $\mathrm{V}_{\mathrm{dn}}$ é o valor normalizado, adimensional $\mathrm{V}_{\mathrm{n}}$ o valor normatizado; $\mathrm{V}_{\text {min }}$ é o valor mínimo da amostra e $\mathrm{V}_{\text {max }}$ o valor máximo da amostra.

Após a escolha da melhor configuração do MLP foram feitos gráficos de superfície resposta para a área foliar observada e estimada para todas as amostras estudadas em função da largura e comprimento do limbo foliar com o auxílio do software SigmaPlot v.11.0. A fim de se verificar a consequência do uso da área foliar estimada em relação à área observada na seleção de plantas, foram estimados os parâmetros genéticos em nível de planta, considerando a avaliação de uma folha e o valor médio de duas e três folhas por planta. $\mathrm{O}$ modelo utilizado para a análise de variância foi: $Y_{i j k}=m+t_{i}+b_{j}+e_{i j}+d_{i j k}$. em que: $\mathrm{Y}_{\mathrm{ijk}}=$ observação referente ao k-ésimo indivíduo, do j-ésimo bloco, do i-ésimo genótipo; $\mathrm{m}=$ média geral da variável em análise; $t_{i}=$ efeito do i-ésimo genótipo $(i=1,2, \ldots, I) ; b_{j}=$ efeito do j-ésimo bloco $(\mathrm{j}=1,2, \ldots, \mathrm{J})$; $\mathrm{e}_{\mathrm{ij}}=$ efeito da interação entre o i-ésimo genótipo do $\mathrm{j}$-ésimo bloco; $\mathrm{d}_{\mathrm{ijk}}=$ efeito do k-ésimo indivíduo dentro da ij-ésima parcela. Todos os efeitos do modelo foram assumidos como aleatórios, sendo que $\mathrm{K}$ é o número de plantas por parcela, J é o número de blocos, I é o número de genótipos. As expressões utilizadas para estimar os parâmetros genéticos são apresentadas por Cruz et al. (2012).

\section{RESULTADOS E DISCUSSÃO}

A partir da média do $\mathrm{EQM}_{\text {(med) }}$ dos 100 treinamentos para cada configuração de rede, observam-se valores muito próximos, entre 0,0022 e 0,0047 (Tabela 1). Logo, a eficiência do treinamento para as várias configurações não melhorou de acordo com o aumento do número de camadas escondidas e de neurônios; resultados similares foram verificados por Soares et al. (2014). O menor valor do $\mathrm{EQM}_{(\min )}$, de 0,0014 , foi encontrado quando se utilizou 3 camadas escondidas com 6,2 e 4 neurônios, correspondente à configuração apresentada na Figura 1. Nesta figura também são apresentados os pesos sinápticos e os viés obtidos após o treinamento, os quais podem ser utilizados para a obtenção da área foliar estimada a partir do comprimento e largura do limbo foliar. Para isso, pode-se recorrer à seguinte expressão:

$A F_{\text {normatizado }}=W_{4} \times$ Tansig $\left\{W_{3} \times\right.$ Tansig $\left[\mathrm{W}_{2} \times\right.$ Tansig $\left(W_{1} \times\right.$ Entrada + $\left.\left.\left.B_{1}\right)+B_{2}\right]+B_{3}\right\}+B_{4}$. É válido lembrar que antes do uso desta expressão deve-se obter os valores normatizados do comprimento e largura do limbo foliar, e que, após a obtenção da área foliar estimada, deve-se proceder à etapa de desnormatização para obter a unidade de centímetros quadrados.

Para o MLP selecionado, obteve-se o coeficiente de determinação 0,9643 , indicando que $96,43 \%$ da informação da área foliar observada foi explicada pela área foliar estimada por meio de MLP. Em trabalho similar com a cultura da pimenta, utilizando RNA, Ahmadian (2012) encontrou resultados próximos $\left(\mathrm{R}^{2}=98 \%\right)$ ao encontrado neste trabalho, concordando com Odabas et al. (2013) para predição da área foliar em plantas de milho que também acharam coeficiente de determinação de $98 \%$. Segundo estes autores, as RNAs são ferramenta fáceis e eficientes para estimar a área foliar.

Para a melhor visualização da eficiência de predição da área foliar pelas RNAs são apresentados na figura 2 os valores observados em função dos

Tabela 1. Média do erro quadrático médio [Eqm $\left.{ }_{(\mathrm{med})}\right]$ para os 100 treinamentos em cada configuração de rede e menor valor de erro quadrado médio $\left[\mathrm{EQM}{ }_{(\mathrm{min})}\right]$ encontrados em cada configuração de rede, acompanhados de seus respectivos coeficientes de determinação \{average of mean squared error [EQM ${ }_{\text {(med) }}$ ] for 100 trainings in each network configuration and the lower mean square error $\left[\mathrm{EQM}_{(\mathrm{min})}\right]$ encountered in each network configuration, accompanied by their respective coefficients of determination $\}$. Diamantina, UFVJM, 2013.

\begin{tabular}{|c|c|c|c|c|c|c|c|}
\hline $\begin{array}{l}\text { Config. } \\
\text { de rede }^{1}\end{array}$ & $\begin{array}{c}\text { EQM } \\
\text { (med) }\end{array}$ & $\begin{array}{c}\text { EQM } \\
(\mathrm{min})\end{array}$ & $\mathbf{R}^{2}$ & $\begin{array}{l}\text { Config. } \\
\text { de rede }\end{array}$ & $\begin{array}{c}\mathbf{E Q M} \\
\text { (med) }\end{array}$ & $\begin{array}{c}\text { EQM } \\
(\min ) \\
\end{array}$ & $\mathbf{R}^{2}$ \\
\hline $2: 1$ & 0,0022 & 0,0018 & 0,9641 & $2: 6: 6: 1$ & 0,0022 & 0,0016 & 0,9502 \\
\hline $4: 1$ & 0,0022 & 0,0017 & 0,9614 & $4: 2: 2: 1$ & 0,0031 & 0,0018 & 0,9637 \\
\hline $6: 1$ & 0,0022 & 0,0017 & 0,9547 & $4: 2: 4: 1$ & 0,0022 & 0,0017 & 0,9610 \\
\hline $2: 2: 1$ & 0,0022 & 0,0018 & 0,9649 & $4: 2: 6: 1$ & 0,0024 & 0,0014 & 0,9643 \\
\hline 2:4:1 & 0,0022 & 0,0016 & 0,9579 & $4: 4: 2: 1$ & 0,0027 & 0,0017 & 0,9628 \\
\hline $2: 6: 1$ & 0,0022 & 0,0017 & 0,9579 & $4: 4: 4: 1$ & 0,0022 & 0,0016 & 0,9620 \\
\hline $4: 2: 1$ & 0,0037 & 0,0015 & 0,9651 & $4: 4: 6: 1$ & 0,0021 & 0,0016 & 0,9637 \\
\hline $4: 4: 1$ & 0,0022 & 0,0017 & 0,9530 & $4: 6: 2: 1$ & 0,0022 & 0,0016 & 0,9539 \\
\hline $4: 6: 1$ & 0,0022 & 0,0016 & 0,9588 & $4: 6: 4: 1$ & 0,0022 & 0,0018 & 0,9586 \\
\hline $6: 2: 1$ & 0,0025 & 0,0017 & 0,9586 & $4: 6: 6: 1$ & 0,0022 & 0,0016 & 0,9610 \\
\hline $6: 4: 1$ & 0,0022 & 0,0018 & 0,9434 & $6: 2: 2: 1$ & 0,0022 & 0,0017 & 0,9514 \\
\hline $6: 6: 1$ & 0,0022 & 0,0017 & 0,9557 & $6: 2: 4: 1$ & 0,0026 & 0,0016 & 0,9541 \\
\hline $2: 2: 2: 1$ & 0,0033 & 0,0018 & 0,9481 & $6: 2: 6: 1$ & 0,0023 & 0,0017 & 0,9594 \\
\hline $2: 2: 4: 1$ & 0,0026 & 0,0018 & 0,9510 & $6: 4: 2: 1$ & 0,0022 & 0,0017 & 0,9588 \\
\hline $2: 2: 6: 1$ & 0,0035 & 0,0017 & 0,9471 & $6: 4: 4: 1$ & 0,0021 & 0,0016 & 0,9520 \\
\hline $2: 4: 2: 1$ & 0,0047 & 0,0018 & 0,9555 & $6: 4: 6: 1$ & 0,0023 & 0,0016 & 0,9584 \\
\hline $2: 4: 4: 1$ & 0,0022 & 0,0017 & 0,9557 & $6: 6: 2: 1$ & 0,0021 & 0,0016 & 0,9582 \\
\hline $2: 4: 6: 1$ & 0,0026 & 0,0018 & 0,9563 & $6: 6: 4: 1$ & 0,0024 & 0,0016 & 0,9483 \\
\hline $2: 6: 2: 1$ & 0,0029 & 0,0018 & 0,9514 & $6: 6: 6: 1$ & 0,0022 & 0,0018 & 0,9516 \\
\hline $2: 6: 4: 1$ & 0,0023 & 0,0017 & 0,9551 & - & - & - & - \\
\hline
\end{tabular}

${ }^{1}$ Número de neurônios por camada (number of neurons per layer). 


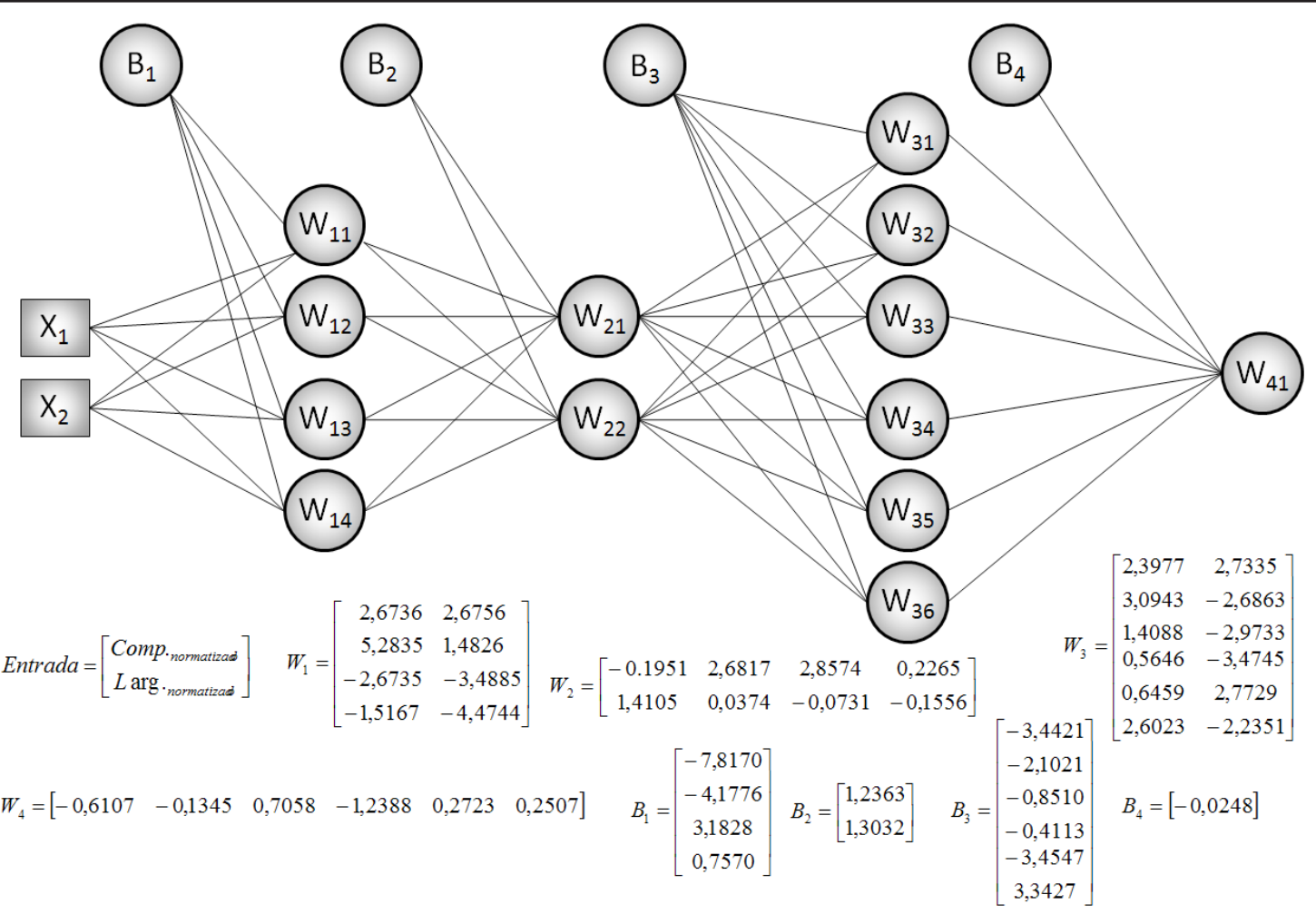

Figura 1. Configuração da RNA selecionada com seus pesos sinápticos (W) e viés (B) para a estimação da área foliar a partir do comprimento $\left(\mathrm{X}_{1}\right)$ e largura do limbo foliar $\left(\mathrm{X}_{2}\right)$ em genótipos de couve \{configuration of RNA selected with their synaptic weights (W) and bias (B) for the estimation of leaf area from length RNA $\left(\mathrm{X}_{1}\right)$ and width of the leaf blade $\left(\mathrm{X}_{2}\right)$ in genotypes of kale . Diamantina, UFVJM, 2013.
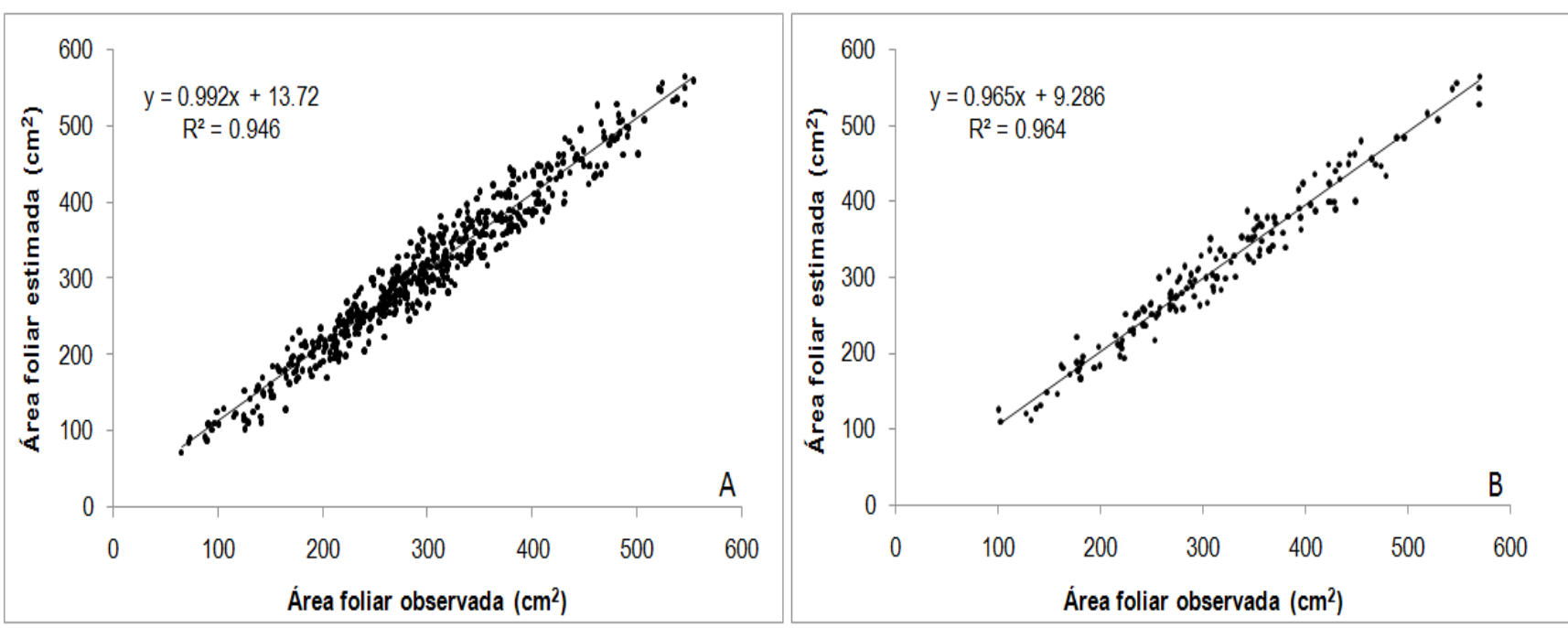

Figura 2. Comparação entre os dados de área foliar observada e estimada $\left(\mathrm{cm}^{2}\right)$ obtidos por redes neurais artificiais para todos os 1100 dados analisados (A) e para a amostra teste (B) em genótipos de couve \{comparison between the data observed and estimated of leaf area $\left(\mathrm{cm}^{2}\right)$ obtained by artificial neural networks for all 1100 data analyzed in (A) and the test sample (B) on genotypes of kale $\}$. Diamantina, UFVJM, 2013.

valores estimados da área para todos os dados amostrais e para a amostra de teste. Segundo Wang \& Zhang (2012) e Fallovo et al. (2008), a eficiência da predição pelas RNAs depende da variação do formato da folha (comprimento / largura) dos materiais genéticos utilizados no treinamento. Assim, a utilização do grande número de genótipos de couve estudados neste artigo, contribui para que a rede treinada seja generalista para vários formatos e tamanhos de folha.

Nas figuras $3 a$ e $3 b$ verifica-se alta irregularidade da área foliar observada em função do comprimento e largura 


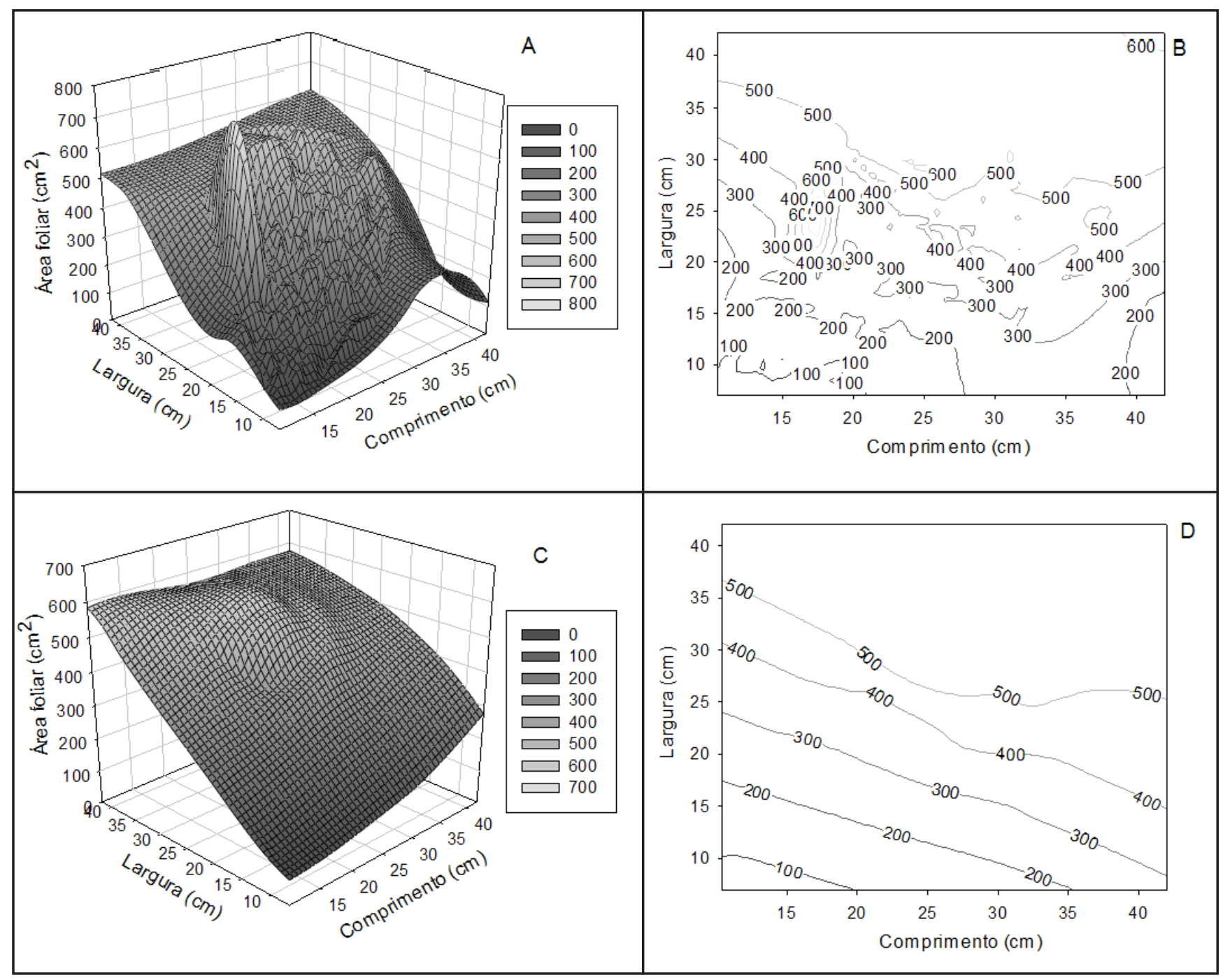

Figura 3. Gráficos de superfície para a área foliar observada (A e B) e estimada por RNAs (C e D) em função do comprimento e largura foliar de 1100 folhas comercializáveis colhidas em 22 genótipos de couve \{surface charts for observed leaf area (A and B) and estimated by RNA (C and D) depending on the length and leaf width of 1100 marketable leaves harvested in 22 genotypes of kale $\}$. Diamantina, UFVJM, 2013.

foliar. Esta irregularidade pode ser explicada pela imprecisão em se avaliar a área foliar de folhas de couve, pois para alguns genótipos encontram-se folhas de superfície bastante engruvinhada. A consequência desta irregularidade na superfície foliar é a obtenção de mensurações que podem ser superestimadas ou subestimadas. Porém, houve uma melhor regularidade para a área foliar estimada em função do comprimento e largura do limbo foliar pelo MLP nas Figuras $3 \mathrm{c}$ e $3 \mathrm{~d}$.

$\mathrm{Na}$ tabela 2 verifica-se que os parâmetros genéticos obtidos para a área foliar estimada são sempre mais favoráveis para a seleção quando comparada com os obtidos para a área foliar observada. Quando se conside- rou a seleção de plantas baseada nas informações de uma folha por planta, a herdabilidade foi de 39,8 e 46,96 para a área foliar observada e estimada, respectivamente, indicando maior sucesso com a seleção para a área foliar estimada pela RNA. Segundo Ramalho et al. (2012), a herdabilidade estima a confiabilidade do valor fenotípico como indicador do valor reprodutivo.

$\mathrm{O}$ efeito de genótipo que era não significativo pelo teste $\mathrm{F}$ para a área foliar observada, passou a ser significativo para a área foliar estimada (tabela 2). Considerando o efeito de tratamento (acessos) como aleatório, isto indica que a variabilidade genética passou a ser considerável em termos de significância estatística, evidenciando a viabilidade da prática da seleção para obtenção de genótipos superiores. A maior precisão no uso da área foliar estimada no processo de seleção também pode ser verificada pela redução do coeficiente de variação ambiental e aumento do índice de variação, que indicam a possibilidade de obter sucesso com a seleção de plantas (Azevedo et al., 2012).

Quando se considera a média de duas e de três folhas por planta as estimativas dos parâmetros genéticos para a área foliar estimada continuam sendo mais favoráveis, contudo se aproximam mais das estimativas obtidas pela área foliar observada. Isso pode ser explicado pelo uso da média que tende a amenizar os desvios proporcionados pela imprecisão de mensuração da área 
Tabela 2. Estimativas de parâmetros genéticos para a área foliar observada (AFO) e estimada (AFE) considerando uma folha e a média de duas e três folhas por planta em 22 genótipos de couve estimates of genetic parameters for leaf area observed (AFO) and estimated (AFE) considering one leaf and the average of two and three leaves per plant on 22 genotypes of kale\}. Diamantina, UFVJM, 2013.

\begin{tabular}{|c|c|c|c|c|c|c|}
\hline \multirow{2}{*}{ Parâmetros } & \multicolumn{2}{|c|}{1 folha } & \multicolumn{2}{|c|}{2 folhas } & \multicolumn{2}{|c|}{3 folhas } \\
\hline & AFO & AFE & AFO & AFE & AFO & AFE \\
\hline $\begin{array}{l}\text { p-valor para o efeito de } \\
\text { genótipo }(\%)\end{array}$ & 6,30 & 2,79 & 0,45 & 0,39 & 0,44 & 0,33 \\
\hline Herdabilidade & 39,80 & 46,96 & 57,77 & 58,39 & 57,82 & 59,12 \\
\hline $\begin{array}{l}\text { Coeficiente de variação } \\
\text { residual-CVe }(\%)\end{array}$ & 18,23 & 17,48 & 15,56 & 14,91 & 16,04 & 15,67 \\
\hline $\begin{array}{l}\text { Coeficiente de variação } \\
\text { genético-CVg }(\%)\end{array}$ & 7,41 & 14,05 & 9,10 & 8,83 & 9,39 & 9,42 \\
\hline $\begin{array}{l}\text { Índice de variação (CVg / } \\
\text { CVe ) }\end{array}$ & 0,49 & 0,59 & 0,69 & 0,72 & 0,68 & 0,70 \\
\hline $\begin{array}{l}\text { Correlação Fenotípica (AFO } \\
\text { x AFE) }\end{array}$ & \multicolumn{2}{|c|}{0,93} & \multicolumn{2}{|c|}{0,98} & \multicolumn{2}{|c|}{0,98} \\
\hline $\begin{array}{l}\text { Correlação Genotípica entre } \\
\text { (AFO x AFE) }\end{array}$ & \multicolumn{2}{|c|}{0,91} & \multicolumn{2}{|c|}{0,99} & \multicolumn{2}{|c|}{0,99} \\
\hline $\begin{array}{l}\text { Correlação Residual entre } \\
\text { (AFO x AFE) }\end{array}$ & \multicolumn{2}{|c|}{0,95} & \multicolumn{2}{|c|}{0,96} & \multicolumn{2}{|c|}{0,97} \\
\hline
\end{tabular}

foliar observada em alguns genótipos. A alta correlação fenotípica e genotípica encontrada entre a área foliar observada e estimada aliada à facilidade e precisão da obtenção da largura e comprimento da folha de couve indicam a viabilidade de usar a área foliar estimada por RNA para a seleção de genótipos superiores.

\section{AGRADECIMENTOS}

À Fundação de Amparo à Pesquisa do estado de Minas Gerais (FAPEMIG), ao Conselho Nacional de Desenvolvimento Científico e Tecnológico (CNPq) e à Coordenação de Aperfeiçoamento de Pessoal de Nível Superior (CAPES) pela concessão de bolsas de estudos e recursos financeiros para o desenvolvimento do projeto.

\section{REFERÊNCIAS}

AHMADIAN-MOGHADAM, H. 2012. Prediction of pepper (Capsicum annuum) leaf area using group method of data handling-type neural networks. International Journal of
AgriScience 2: 993-999.

AZEVEDO, AM; ANDRADE JÚNIOR, VC; PEDROSA, CE; FERNANDES, JSC; VALADARES, NR; FERREIRA, MRA; MARTINS, RAV. 2012. Desempenho agronômico e variabilidade genética em genótipos de couve. Pesquisa Agropecuária Brasileira 47: 1751-1758.

BLANCO, FF; FOLEGATTI, MV. 2003. A new method for estimating the leaf area index of cucumber and tomato plants. Horticultura Brasileira 21: 666-669.

CHO, YY; OH, S; OH, MM; SON, JE. 2007. Estimation of individual leaf area, fresh weight, and dry weight of hydroponically grown cucumbers (Cucumis sativus L.) using leaf length, width, and SPAD value. Scientia Horticulturae 111: 330-334.

CRUZ, CD; REGAZZI, AJ. ; CARNEIRO, PCS. 2012. Modelos biométricos aplicados ao melhoramento genético. Viçosa: Editora UFV. $514 \mathrm{p}$

DE SWART, EAM; GROENWOLD, R; KANNE, HJ; STAM, P; MARCELIS, LFM; VOORRIPS, RE. 2004. Non-destructive estimation of leaf area for different plant ages and accessions of Capsicum annuиm L. Journal of Horticultural Science and Biotechnology 79: 764-770.

DEMIRSOY, H; DEMIRSOY, L; OZTURK, A. 2005. Improved model for the non-destructive estimation of strawberry leaf area. Fruits 60 : 69-73.

EMBRAPA. 2006. Centro Nacional de Pesquisa em Solos. Sistema brasileiro de classificação de solos. Brasília: Embrapa-SPI; Rio de Janeiro: Embrapa-Solos. 306p.

FALLOVO, C; CRISTOFORI, V; GYVES, EM; RIVERA, CM; REA, ROBERTO; FANASCA, S. 2008. Leaf area estimation model for small fruits from linear measurements. Hortscience 43: 2263-2267.

FILGUEIRA, FAR. 2008. Novo manual de olericultura: Agrotecnologia moderna na produção e comercialização de hortaliças. Viçosa: Editora UFV. 402p.

GHOREISHI, M; HOSSINI, Y; MAFTOON, M. 2012. Simple models for predicting leaf area of mango (Mangifera indica L.). Journal of Biology and Earth Sciences 2: 45-53.

ODABAS, MS; ERGUN, E; ONER, F. 2013. Artificial neural network approach for the predicition of the corn (Zea mays L.) leaf area. Bulgarian Journal of Agricultural Science 19: 766-769.

RAMALHO, MAP; ABREU, AFB; SANTOS, JB; NUNES, JAR. 2012. Aplicações da genética quantitativa no melhoramento de plantas autógamas. Lavras: UFLA. 522p.

ROUPHAEL, Y; RIVERA, CM; CARDARELLI, M; FANASCA, S; COLLA, G. 2006. Leaf area estimation from linear measurements in zucchini plants of different ages. Journal of Horticultural Science and Biotechnology 81: 238-241.

SALERNO, A; RIVERA, CM; ROUPHAEL, Y; COLLA, G; CARDARELLI, M; PIERANDREI, F; REA, E; SACCARDO, F. 2005. Leaf area estimation of radish from linear measurements. Advances in Horticultural Science 19: 213-215.

SILVA, EC; VELLASCO, MMBR; BARBOSA, CR; HALL, M; ELISABETH, C; GUSMÃO, LAP. 2012. Modelagem da sensibilidade de amostras GMI por redes neurais. Sba: Controle \& Automação Sociedade Brasileira de Automatica 23: 636-648.

SILVA, GN; TOMAZ, RS; SANT'ANNA, IC; NASCIMENTO, M; BHERING, LL; CRUZ, CD. 2014. Neural networks for predicting breeding values and genetic gains. Scientia Agricola 71: 494-498.

SILVA, SHMG; LIMA, JD; BENDINI, HN; NOMURA, ES; MORAES, WS. 2008. Estimativa da área foliar do antúrio com o uso de funções de regressão. Ciência Rural 38: 243-246.

SOARES, FC; ROBAINA, AD; PEITER, MX; RUSSI, JL; IVAN, GA. 2014. Redes neurais artificiais na estimativa da retenção de água do solo. Ciência Rural 44: 293-300.

STOPPANI, MI; WOLF, R; FRANCESCANGELI, N; MARTÍ, HR. 2003. A nondestructive and rapid method for estimating leaf area of broccoli. Advances in Horticultural Science 17: 173-175.

WANG, Z; ZHANG, L. 2012. Leaf shape alters the coefficients of leaf area stimation models for Saussurea stoliczkai in central Tibet. Photosynthetica 50: 337-342. 